\title{
Factors Predicting Heart Failure in Children Admitted to a Pediatric Emergency Ward in a Developing Country
}

\author{
Uchenna Onubogu \\ Rivers State University Teaching Hospital, Port Harcourt - Nigeria
}

\section{Abstract}

Background: Heart failure is an important cause of morbidity and mortality in children.

Objective: To determine the clinical characteristics of children with acute heart failure syndrome in the emergency ward of River state university teaching hospital, Nigeria and identify factors associated with poor outcomes.

Methods: This was an 18 month retrospective review of the acute heart failure register. Poor outcome measures were defined as the persistence of heart failure after 4 days on admission or death.

Results: Ninety-two (4.1\%) of 2,244 children admitted were in heart failure, Non-cardiac disorders [bronchopneumonia 32(36\%), sepsis $21(24 \%)$, severe malaria $10(11 \%)$, sickle cell anaemia $8(9 \%)$ and tuberculosis $3(3 \%)$ ] contributed to $74(83 \%)$ while congenital heart disease(CHD) was $15(17 \%)$. Seventy-four ( $83 \%)$ were discharged, 10(11\%) died and 4(5\%) left against medical advice. The median time to resolution of heart failure was significantly 24 hours longer for malnourished children than those with normal-nutritional status, $72 \mathrm{Vs} 48 \mathrm{hrs}, \log$ rank:0.001. Those with modified Ross score of $>7$ and sepsis were more likely to die, OR,8.8(95\% CI,1.2 to 72.5,p = 0.02 ) and 3.9(95\% CI,1.01 to 15.2; $\mathrm{p}=0.04)$. Age $<2 \mathrm{yrs}(\mathrm{OR}, 3.1, \mathrm{CI}, 1.2$ to $8.5, \mathrm{p}=0.02)$, and $\mathrm{CHD}$ (OR 3.6,95\% CI,1.1 to $12, \mathrm{P}=0.02)$ were associated with a higher likelihood of having a poor outcome. Each unit increase in weight for age $\mathrm{Z}$ score of 1 , decreased the odds of having a poor outcome, OR,0.77 (95\% CI,0.63 to 0.95)p=0.016.

Conclusion: Heart failure in our setting is predominantly caused by non-cardiac disorders. Modified Ross score of $>7$ and sepsis are risk factors for mortality in children with heart failure. (Int J Cardiovasc Sci. 2020; 33(6):673-685)

Keywords: Child; Heart Failure; Pediatric Emergency; Mortality and Morbidity; Critical Care Outcomes; Emergency Service, Hospital.

\section{Introduction}

Heart failure is a clinical syndrome that occurs when the heart is unable to meet the metabolic needs of the body in the presence of adequate ventricular filling. ${ }^{1}$ It is an important cause of morbidity and mortality in children $^{2,3}$. Heart failure accounted for $5971(0.02 \%)$ annual pediatric emergency room visits in a U.S. national survey. ${ }^{4}$ In Nigeria, heart failure accounted for 6 to $16 \%$ of hospital admissions in both emergency rooms and pediatric wards..$^{5-8}$

In the emergency department, children with heart failure are a heterogeneous group of patients who could have a primary cardiac pathology or a secondary pathology of non-cardiac origin. ${ }^{3}$ The emergency department acts as the first point of call for these children, and the emergency doctor has the primary responsibility of identifying these patients and promptly commencing management ${ }^{9,10}$. When children present with heart failure in developed countries, the most common reason is complications from a congenital or post-operative cardiac condition, while in developing countries, complications from non-cardiac conditions are the most predominant cause.${ }^{11}$

Because acute heart failure syndrome is most often from secondary causes in developing countries, it tends to

Mailing Address: Uchenna Onubogu

6-8 Harley street, Forces Avenue. Postal code: 500241, Port Harcourt - Nigeria

E-mail: utchayonubogu@yahoo.co.uk 
be under-recognized, since it is obscured by the primary diagnosis. These children are very ill, and by the time acute heart failure complicates a primary pathology it is usually seen at the extreme spectrum of the disease. Early recognition of heart failure would prompt early commencement of cardiac support, which invariably leads to better outcomes in children presenting with heart failure.

There is limited data on the burden of acute heart failure in children in sub-Saharan Africa and factors associated with poor outcomes. There is also a need to understand the characteristics of acute heart failure and outline its management strategies in the pediatric age group. ${ }^{11,12}$

Thus, we set out to determine the prevalence of acute heart failure in the emergency ward of our hospital, describe the clinical characteristics and determine the outcomes of children admitted with acute heart failure. It is hoped that the results will help increase early recognition of acute heart failure syndrome in children, especially in emergency settings, and that the identification of factors associated with poor outcomes will improve the efficiency of clinical management and achieve better outcomes.

\section{Materials and Methods}

\section{Aims and Objectives of the Research Project}

To determine the clinical characteristics of children with acute heart failure syndrome in the emergency room and identify factors associated with poor outcomes.

\section{Study Setting}

Rivers State University Teaching Hospital (formerly known as Braithwaite Memorial Specialist Hospital) is a tertiary hospital located in Port Harcourt, Rivers State, Nigeria. The pediatric department contains 80 beds, including 12 in the emergency ward. The pediatric emergency department treats an average of 1724 children annually. Patients admitted through the emergency department are first evaluated by the resident physician, whose activity is overseen by a supervising consultant. Admitted patients are given urgent treatment, followed by transfer to the main pediatric ward within $48 \mathrm{hrs}$ of admission if they are determined to be clinically stable. Patients who respond to treatment can also be discharged from the emergency room within 24 hours.

\section{Selection Criteria}

This is a retrospective review of prospectively collected data from acute heart failure records of the pediatric emergency ward between March 2014 and July 2015. Children who presented in the emergency ward with the cardinal signs of heart failure were identified by the attending physician. The criteria for diagnosing heart failure were the presence of hepatomegaly with any two of the following: ${ }^{8}$ 1) significant tachycardia, which is resting heart rate greater than the following cut-offs for different ages: $160 \mathrm{bpm}$ in infants, $150 \mathrm{bpm}$ in children $>1-2$ years of age, $140 \mathrm{bpm}$ in children $>2-4$ years, $120 \mathrm{bpm}$ in children $>4-6$ years and $100 \mathrm{bpm}$ in children $>6$ years (febrile children were allowed an additional 10bpm for every degree rise in temperature above normal); 2) tachypnea, which is resting respiratory rate above the following cut-offs; $60 \mathrm{bpm}$ in infants $<2$ months old, $50 \mathrm{bpm}$ in infants 2-12 months old, $40 \mathrm{bpm}$ in children $>1$ year old; 3 ) cardiomegaly, which is a displaced apex beat in the presence of a central trachea or a cardiothoracic ratio of $>60 \%$ in children $\leq 5$ years of age and $>50 \%$ in older children. Children diagnosed with heart failure whose parents gave consent were included in the study. Apart from excluding children whose parents who did not give consent, we also excluded neonates (children aged $\leq 28$ days old), since they are usually admitted into the special-care baby unit, which is separate from the pediatric emergency ward.

\section{Data Collection}

After initial resuscitative treatment had been carried out to stabilize the patients, a member of the research team approached the parents and patient to inform them about the study and to receive formal consent for inclusion. Once recruited, the patients were followed up throughout their stay in the hospital, from the emergency room to the main hospital ward stay until discharge. An interviewer administered a questionnaire to the parents, and a study number was allocated to the patient. Data was collected using a structured proforma and was updated daily. The following information was collected: age, gender, referral pattern, social class, weight, temperature, respiratory rate, heart rate, presence of hepatomegaly, previous treatment, modified Ross score, packed cell volume, white blood cell count, primary diagnosis, treatments given, diagnosis, length of hospital stay, and outcome of admission.

Social class was categorized according to the parent's level of education and occupation, from class 1 (highest) to 
class 5 (lowest). ${ }^{13} \mathrm{~A}$ hemoglobin level of less than $8 \mathrm{~g} / \mathrm{dl}$ was described as severe anemia. ${ }^{14}$ The modified Ross criteria were used to classify the severity of heart failure.

Nutritional status was classified using weight-for-age Z-scores ${ }^{15-17}$

\section{Statistical Analysis}

The data were entered into an Excel spreadsheet and analyzed using IBM SPSS statistics version 23. Univariate descriptive statistics were used to explain the patient's characteristics with measures of central tendency and dispersion. Kaplan-Meier survival curves were generated for resolution of heart failure by 1 week (168 hrs) after admission, and a log rank test was performed to compare the time to resolution of heart failure in different sub groups. P-values $\leq 0.05$ were considered significant. Post hoc identification of risk factors for poor outcomes was performed using univariate logistic regression for all variables. Variables with a p-value $<0.1$ or with a clinical application relevant to children with a non-cardiac cause of heart failure were put into a multivariate logistic regression model. Backward stepwise elimination was used to determine variables included in the final model. The final model was internally validated using the Hosmer and Lemeshow goodnessof-fit test, with an acceptable fitness set at a $\mathrm{p}>0.05$, and a ROC curve of the new model was constructed to assess its discriminatory accuracy.
The primary outcome measures were the persistence of heart failure $>4$ days after admission or death. The results are reported as odds ratio with $95 \%$ confidence interval.

Informed consent was required from all participating patients, although refusal did not affect the patient's hospital management. Ethical clearance was obtained from the ethics committee of the Rivers State Hospital Management Board, Port Harcourt, Nigeria.

\section{Results}

A total of 2,244 patients were admitted to the children's emergency ward, of whom 92(4.1\%) were diagnosed with heart failure. The parents or guardians of all patients gave informed consent prior to registration in the database. Three patients with incomplete data were excluded from the analysis, while the remaining 89 were analyzed (Figure I).

\section{Characteristics of the Study Population}

The included children ranged from one month to 16 years of age, with a median age of 11 months (IQR: 5- 38 months). There were $45(51 \%)$ males, with a maleto-female ratio of 1.1:1. Most patients $72(81 \%)$ lived in urban areas, belonged to the middle class 52(58\%), and lived with both of their parents $80(90 \%)$. Most presented directly to the hospital 53(60\%) without being referred, although $67(75 \%)$ had taken medication before presenting to the hospital. Of those who had taken medication prior to admission, 28(42\%) took prescription medication while 10(15\%) took herbal medications (Table 1).

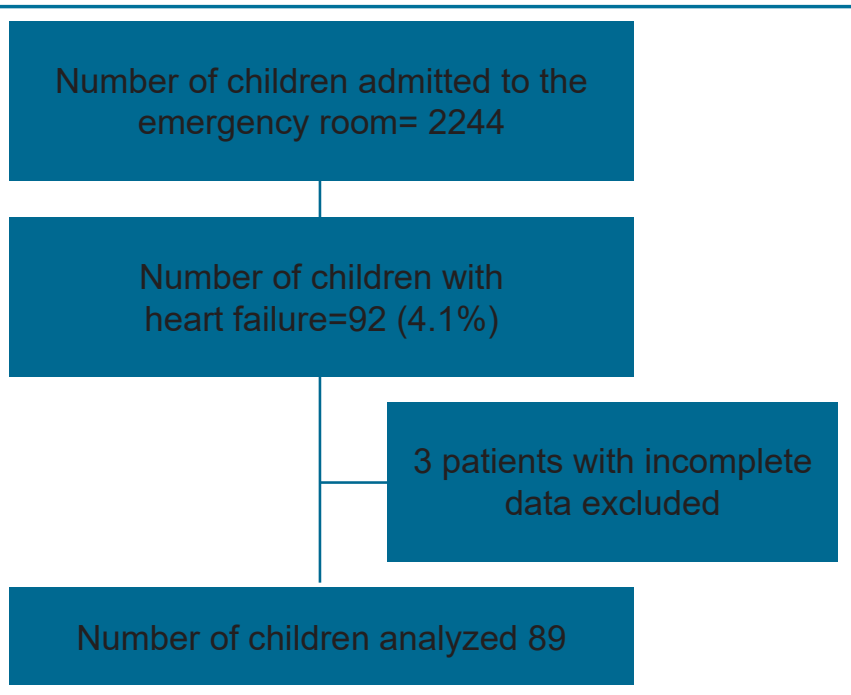

Figure 1 - Study flow chart. 
Table 1 - Characteristics of studied patients

\begin{tabular}{|c|c|}
\hline Variable & All patients $(n=89)(\%)$ \\
\hline $\begin{array}{l}\text { Age months (Median, } 25^{\text {th }}, 75^{\text {th }} \\
\text { percentile) }\end{array}$ & $11(5,38)$ \\
\hline $1 \mathrm{month}$ to $\geq 5 \mathrm{yrs}$ & $72(81)$ \\
\hline$>5$ to $10 \mathrm{yrs}$ & $11(12)$ \\
\hline$>10 \mathrm{yrs}$ & $6(7)$ \\
\hline \multicolumn{2}{|l|}{ Gender } \\
\hline Female & $44(49)$ \\
\hline Male & $45(51)$ \\
\hline \multicolumn{2}{|l|}{ Residence } \\
\hline Urban & $72(81)$ \\
\hline Rural & $17(19)$ \\
\hline \multicolumn{2}{|l|}{ Who child resides with } \\
\hline Both parents & $80(90)$ \\
\hline Single parent & $5(6)$ \\
\hline other & $4(4)$ \\
\hline \multicolumn{2}{|l|}{ Social class of parents } \\
\hline Upper class (1 to 1.7 ) & $9(10)$ \\
\hline Middle class (1.8 to 3.3 ) & $52(58)$ \\
\hline Lower class (3.4 to 5) & $28(32)$ \\
\hline \multicolumn{2}{|l|}{ Prior treatment } \\
\hline Yes to medications & $67(75)$ \\
\hline No to medications & $22(25)$ \\
\hline \multicolumn{2}{|l|}{ Prior Medications (N=67) } \\
\hline Prescribed & $28(42)$ \\
\hline Over-the-counter & $29(43)$ \\
\hline Herbal & $10((15)$ \\
\hline
\end{tabular}

\section{Clinical Features of Children with Heart Failure}

Forty-six (52\%) of the children were malnourished, of whom $32(36 \%)$ were severely malnourished. The median hemoglobin level was 8.6(IQR 6.3,11) g/dl, and 41(46\%) patients were severely anemic (with a hemoglobin level of less than $8 \mathrm{~g} / \mathrm{dl}$ ), while $10(11 \%$ ) had dysmorphic features suggestive of Down syndrome. Sixty-seven (75\%) had moderate heart failure according to the modified Ross classification. Non-cardiac disorders contributed to heart failure in $74(83 \%)$ cases. The most common causes of heart failure were bronchopneumonia 32(36\%), sepsis $21(24 \%)$, and congenital heart disease $15(17 \%)$. A blood transfusion was given to $41(46 \%)$ patients, while $64(72 \%)$ received furosemide (Table 2).

\section{Patient Outcomes}

Seventy-four (83\%) of the patients were discharged home, and the median time for resolving heart failure was 60 hours. Seventy-five percent of the discharged patients were discharged by $108 \mathrm{hrs}$. Of the 10(11\%) who died, the median time of death was $180 \mathrm{hrs}$ (range 2 to 24 days), while the median time for those who left against medical advice was $156 \mathrm{hrs}$. One patient was referred to another hospital within $2 \mathrm{~h}$ of admission due to a health worker strike that interrupted services (Table 3 ). Of the 10 children who died, 3 had bronchopneumonia and 5 had sepsis; only one had a diagnosed congenital heart defect and one had severe malaria. The median time to resolution of heart failure with a modified Ross score $<2$ was significantly longer for malnourished children than those with a normal nutritional status (72 Vs 48hrs, log-rank : 0.001; see Figure 2). Although a modified Ross score $>7$ was associated with a relatively longer recovery time (72 vs, $48 \mathrm{hrs}$.), the difference was not statistically significant (log-rank: 0.2 ; see Figure 3). Children with a modified Ross score $>7$ and those with sepsis were more likely to die, with odds ratios of 8.8 (CI 1.2 to $72.5, \mathrm{p}$ 0.02 ) and 3.9 (CI 1.01 to 15.2, p 0.04), respectively.

\section{Univariate Analysis of Risk Factors Associated with Poor Outcome}

Children less than 2 years of age were more likely to have poor outcomes (OR 3.1, CI 1.2 to 8.5, p=0.02), which were defined as persistence of heart failure 4 days after admission or death. Residential location and family size did not affect the odds of a poor outcome. Dysmorphic features significantly increased the odds of a poor outcome (OR $7.295 \%$ CI 1.5 to $36, \mathrm{P}=0.009$ ), while gender, nutritional status, modified Ross score at admission, prior treatment and anemia did not affect the odds of a poor outcome. Heart failure due to congenital heart disease was associated with a higher likelihood of a poor outcome OR 3.6, 95\% CI 1.1 to $12, \mathrm{P}=0.02$. Each unit increase in Z-score decreased the odds of a poor outcome (OR 0.77, CI 0.63 to 0.95, p=0.016; see Table 4).

Using the clinical relevance of variables for non-cardiac causes of heart failure and a p-value cut-off of 0.1 to select 
Table 2 - Clinical characteristics and treatment of children with heart failure

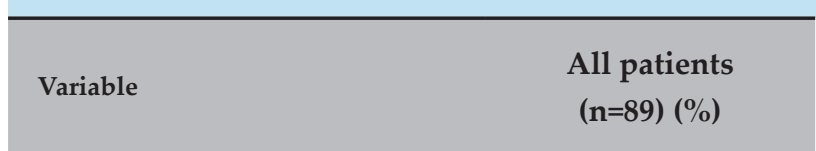

Nutritional status Z-score (median, IQR)

$-2.1(-3.7,-0.5)$

>2SD (Overweight)

2 to $-2 S D$ (Normal)

$<-2$ to -3SD ( Moderate

Malnutrition)

14(16)

$<-3 S D$ (Severe Malnutrition)

Hemoglobin in g/dl (median, IQR)

$$
\begin{aligned}
& \mathrm{Hb}<8 \mathrm{~g} / \mathrm{dl} \\
& \mathrm{Hb}>8 \mathrm{~g} / \mathrm{dl}
\end{aligned}
$$

Dysmorphic features

$$
\text { Yes }
$$

No

Modified Ross score

$$
3 \text { to }<7 \text { (Mild HF) }
$$

7 to $<11$ (Mod HF)

11 to 12 (severe HF)

Cause of Heart Failure

Bronchopneumonia

Sepsis

Congenital heart defect

Severe Malaria

Sickle cell

Tuberculosis

Treatment received

Blood transfusion

Furosemide

Captopril

Spironolactone

Digoxin
Table 3 - Time until outcome

\begin{tabular}{lcc}
\hline Outcome & N (\%) & $\begin{array}{c}\text { Median in hours } \\
(\mathbf{1 Q R})\end{array}$ \\
Heart failure resolved & $74(83)$ & $60(60 ; 108)$ \\
Death & $10(11)$ & $180(60 ; 348)$ \\
$\begin{array}{l}\text { Discharged against } \\
\text { medical advice }\end{array}$ & $4(5)$ & $156(48 ; 216)$ \\
Referred & $1(1)$ & $2(2)$ \\
\hline
\end{tabular}

the model of best fit, the following variables were added into multivariable logistic regression model (Table 5): age less than 2 years, weight-for-age score, and modified Ross score $>7$. This model explained $13.9 \%\left(R^{2}\right)$ of the variance in outcome of heart failure and correctly classified $66.3 \%$ of the cases. The area under curve for the predictability of poor outcome was $64 \%$ (95\% CI; 52 to $76 \%$ ) Figure 4.

\section{Discussion}

The $4.1 \%$ heart failure prevalence seen in this study is similar to the $5.8 \%$ and $2.7 \%$ previously reported in Nigerian studies. ${ }^{8,18}$ Other African countries, including Kenya and Ethiopia, have reported much lower heart failure rates (1:1000 and 2.9\%, respectively). ${ }^{19,20}$ However, the children in the Ethiopian study were relatively older than our sample, and the Kenyan study was a retrospective review of clinical notes, which would have limitations identifying all patients with heart failure. Most European studies ${ }^{21,22}$ on heart failure prevalence have been performed in patient populations with specific cardiac pathologies, thus their findings cannot be compared with ours.

The fact that we excluded neonates, as well as the fact that fetal diagnosis and corrective cardiac surgery are not performed in our department, could mean that most of the children with congenital heart defects who do not survive beyond early neonatal life were excluded from our population. This could mean that the actual prevalence of children with congenital heart defects who may have developed heart failure remained undetected. It may also be indicative of underreporting in developing countries .

As reported in other African studies, non-cardiac causes were the predominant etiology of heart failure. ${ }^{7,18,19}$ Bronchopneumonia has been reported in previous studies as the leading cause of heart failure in children in developing countries. ${ }^{7,19,20}$ In Thai and Nigerian studies of hospitalized 


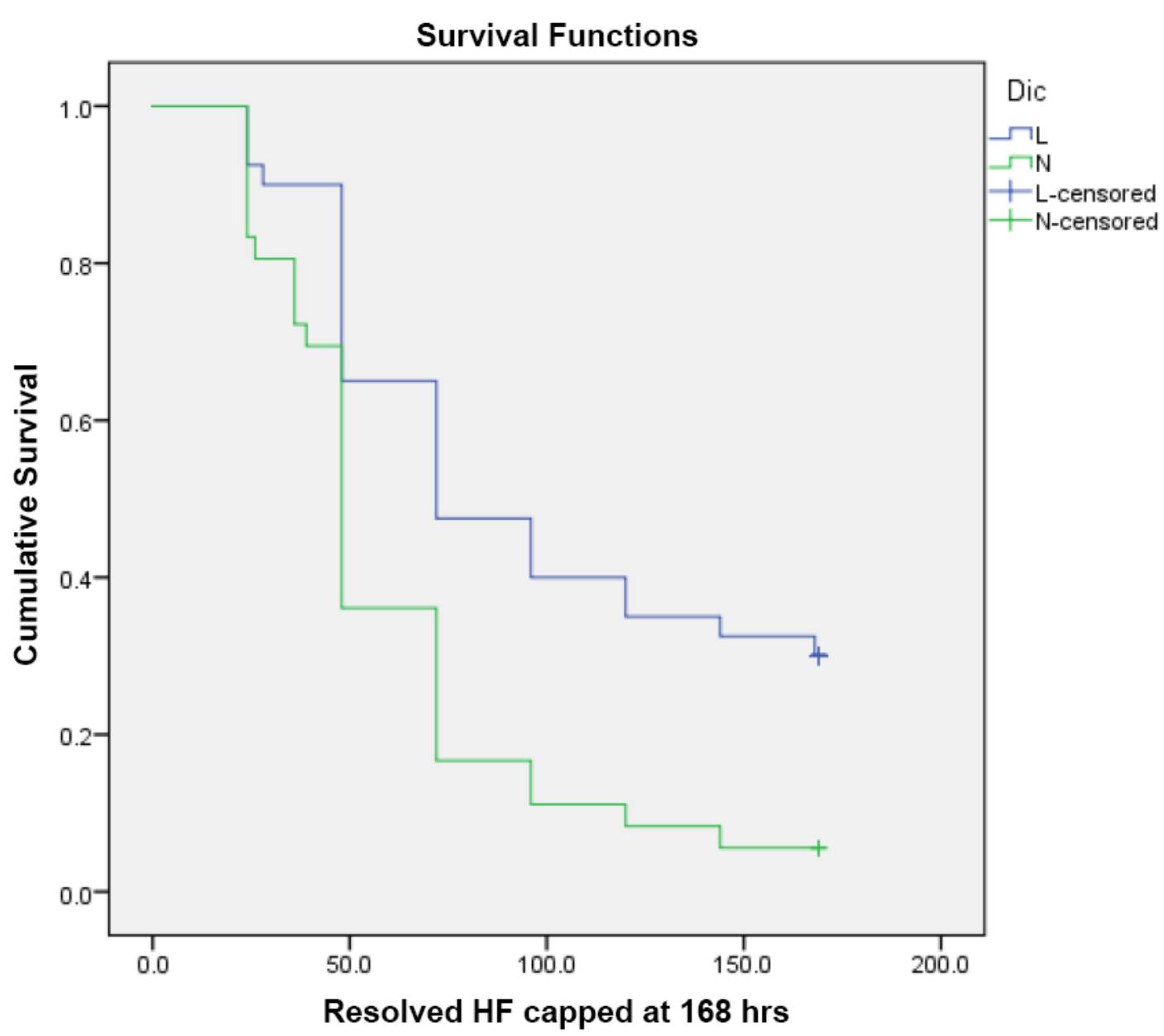

$\mathrm{L}=\mathrm{Z}$ score $<-2$ (Malnourished), $\mathrm{N}=\mathrm{Zscore}>-2$ (Not malnourished), $\mathrm{HF}=$ Heart failure, DIC Zscore $=$ Dichotomized Zscore, Cum Survival $=$ Cumulative survival

\begin{tabular}{lccccc}
\hline & & & \multicolumn{2}{c}{$95 \%$ confidence interval } & Log rank \\
\cline { 3 - 5 } Nutritional status & Mean Hrs & Median(Hrs) & lower & upper & 0.001 \\
L = Malnourished & 99 & 72 & 42 & 102 & 52 \\
N = Not malnourished & 61 & 48 & 44 & \\
\hline
\end{tabular}

Figure 2 - Time to resolution of heart failure according to nutritional status.

under children under 5 years of age, congestive heart failure complicated bronchopneumonia in 10\% and 39.4\% of the patients, respectively. ${ }^{23,24}$ In bronchopneumonia, inflammation of the alveoli and inter alveolar septum increases pulmonary arterial vascular pressure, resulting in an increased afterload on the right ventricle, which can cause the right ventricle to fail if it cannot adequately pump against the raised pulmonary vascular resistance ${ }^{24}$
In a study aimed at assessing the cardiac systolic function of children with severe malaria, $48 \%$ had elevated cardiac troponin I compared to healthy controls, which may be suggestive of myocardial injury. ${ }^{25}$ Myocardial dysfunction in children with severe malaria has been postulated to be caused by acidosis, which depresses the myocardium and has a negatively inotropic effect on the heart. ${ }^{26,27}$ 


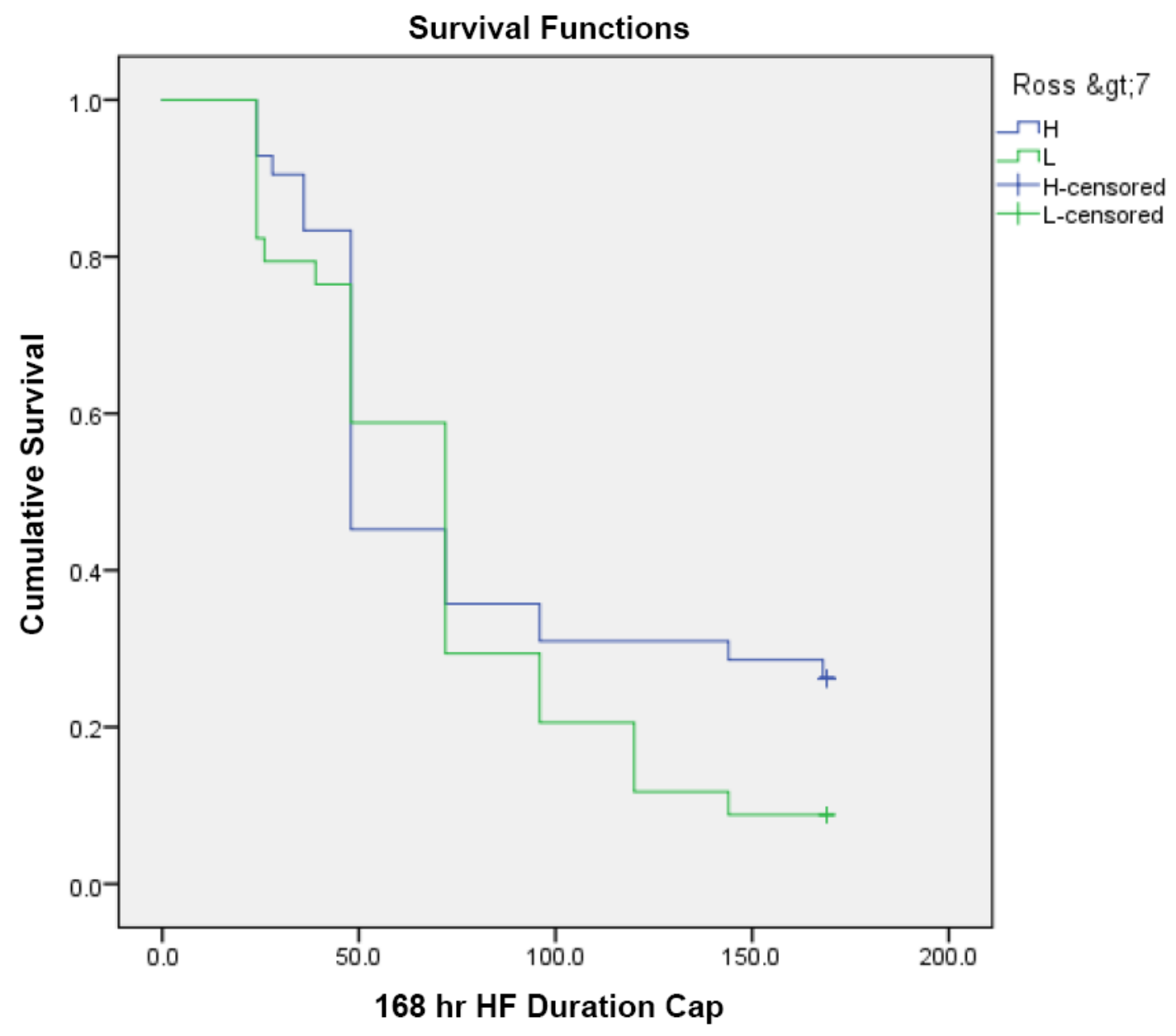

$\mathrm{H}=$ Mod Ross $>$ 7; L=Mod Ross $<7$; Ross $\% g t 7=$ Modified Ross score cut off at 7

\begin{tabular}{lccccc}
\hline Nutritional status & Mean Hrs & Median(Hrs) & \multicolumn{2}{c}{$95 \%$ confidence interval } & Log rank \\
\cline { 3 - 5 } & & & lower & upper & 0.2 \\
$\mathrm{H}=$ Modified Ross score $>7$ & 86 & 48 & 36 & 60 & 84 \\
$\mathrm{~L}=$ Modified Ross score $<7$ & 74 & 72 & 60 & 8 \\
\hline
\end{tabular}

Figure 3 - Time until resolution of heart failure according to modified Ross score at admission.

Malnutrition was associated with a higher likelihood that recovery time from heart failure would be greater than $24 \mathrm{hrs}$. We found a relatively slower recovery time among malnourished patients than has been reported in previous studies. Malnutrition was associated with prolonged intubation time $(12.4 \mathrm{~h})$ and prolonged intensive care unit stay (2.7 days) among children with congenital heart disease undergoing corrective surgery. ${ }^{28}$ In addition, malnutrition exacerbates the symptoms of heart failure by worsening fluid retention, inflammatory response and neurohormonal activation..$^{29}$

Our results show that the severity of heart failure (classified by the modified Ross score) helps stratify the risk of mortality in children with acute heart failure. In a study conducted among a group of children with dilated 
Table 4 - Factors associated with poor outcomes

\begin{tabular}{lccccc}
\hline \multirow{2}{*}{ Variable } & Poor Outcome & & & \multicolumn{2}{c}{$95 \%$ confidence interval } \\
\cline { 3 - 5 } & $(\mathrm{n}=36)(\%)$ & ratio & Lower & Upper
\end{tabular}

Residence

$\begin{array}{lr}\text { Urban } & 32(44) \\ \text { Rural } & 4(24)\end{array}$

$4(24)$

Who child lives with

Both parents

0.1

0.01

Others

Age

$<2 \mathrm{yrs}$

$>2 \mathrm{yrs}$

Gender

Female

Male

0.6

0.3

1.6

Referred

Yes

18(50)

1.9

0.8

4.6

No

18(34)

Social class

Upper

$8(38)$

1.1

0.4

3.2

0.8

Lower

Family size

$>4$ children

1.3

0.5

3.7

0.6

$<4$ children

Nutritional status

Severe Malnutrition

16(50)

1.9

0.8

4.5

0.17

No severe Malnutrition

20(35)

Z-score Weight/age

0.77

0.63

0.95

0.016

Dysmorphia

Yes

$8(80)$

7.2

1.5

36

0.009

No

28(35)

Modified Ross >7

Yes

No

141(38)

Prior treatment

Yes

1.6

0.5

4.5

0.3
No 


\begin{tabular}{|c|c|c|c|c|c|}
\hline \multicolumn{6}{|l|}{ Herbs } \\
\hline Yes & $5(50)$ & 1.5 & 0.4 & 5.6 & 0.3 \\
\hline No & $31(39)$ & & & & \\
\hline \multicolumn{6}{|l|}{ PCV $<24$} \\
\hline Yes & $14(34)$ & 0.6 & 0.3 & 1.4 & 0.2 \\
\hline No & $22(46)$ & & & & \\
\hline \multicolumn{6}{|l|}{ Sepsis } \\
\hline Yes & $9(42)$ & 1.1 & 0.4 & 3.0 & 0.06 \\
\hline No & $27(40)$ & & & & \\
\hline \multicolumn{6}{|c|}{ Bronchopneumonia } \\
\hline Yes & $10(31)$ & 0.5 & 0.2 & 1.3 & 0.1 \\
\hline No & $26(46)$ & & & & \\
\hline \multicolumn{6}{|c|}{ Coronary heart disease } \\
\hline Yes & $10(67)$ & 3.6 & 1.1 & 12 & 0.02 \\
\hline No & $26(35)$ & & & & \\
\hline \multicolumn{6}{|l|}{ Malaria } \\
\hline Yes & $2(20)$ & 0.3 & 0.6 & 1.6 & 0.1 \\
\hline No & $34(43)$ & & & & \\
\hline \multicolumn{6}{|c|}{ Blood transfusion } \\
\hline Yes & $15(36.5)$ & 0.7 & 0.3 & 1.7 & 0.5 \\
\hline No & $21(43)$ & & & & \\
\hline
\end{tabular}

Table 5 - multivariate logistic regression for poor outcome

\begin{tabular}{|c|c|c|c|c|c|c|c|c|c|}
\hline & & \multirow{2}{*}{ B } & \multirow{2}{*}{ SE } & \multirow{2}{*}{ Wald } & \multirow{2}{*}{ df } & \multirow{2}{*}{ Sigma } & \multirow{2}{*}{$\operatorname{Exp}(B)$} & \multicolumn{2}{|c|}{$95 \%$ CI for EXP(B) } \\
\hline & & & & & & & & Lower & Upper \\
\hline \multirow{4}{*}{ Step $1^{\mathrm{a}}$} & Z-scoreWA & -.202 & .112 & 3.261 & 1 & .071 & .817 & .656 & 1.017 \\
\hline & $<2 \operatorname{yr}(1)$ & .837 & .535 & 2.449 & 1 & .118 & 2.310 & .810 & 6.594 \\
\hline & Rossgt7(1) & .310 & .462 & .450 & 1 & .502 & 1.364 & .551 & 3.375 \\
\hline & Constant & -1.585 & .525 & 9.108 & 1 & .003 & .205 & & \\
\hline
\end{tabular}

cardiomyopathy, Ross scale scores $>11$ were significantly associated with death or transplant. ${ }^{30}$ Rocha Araújo et al., ${ }^{31}$ used the recently modified 20-point Ross scale to classify their patients. The Ross scale was expanded from its old version (which incorporated only clinical variables) to include laboratory variables in order to improve its sensitivity for predicting outcomes in children with heart failure. $^{31}$ The following variables were added to the scale: $\mathrm{N}$-terminal pro b-type natriuretic peptide, ejection fraction, systemic atrioventricular valve insufficiency and percentage of predicted maximal oxygen uptake for children 9 years of age and older. ${ }^{31}$ In resource poor settings however, these 


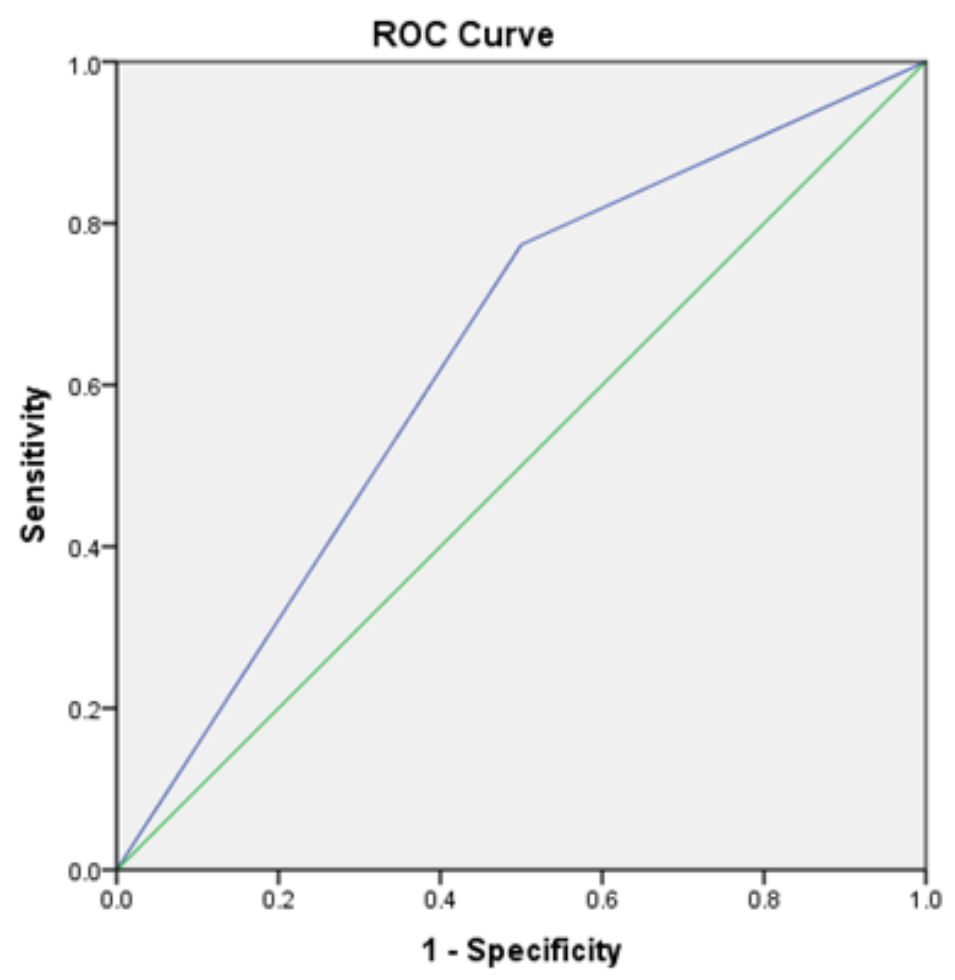

Area Under the Curve

Test Result Variable(s): Predicted group

\begin{tabular}{lcccr} 
& & & & \multicolumn{2}{c}{ Asymptotic 95\% Confidence Interval } \\
\cline { 3 - 5 } Area & Std. Error & Asymptotic Sig. & & Lower Bound \\
\hline .637 & .061 & .029 & .517 & Upper Bound \\
\hline
\end{tabular}

Figure 4- Predictability value for the model, ROC and test results.

laboratory investigations may not easily be available, making the newer Ross classification system more difficult to apply. Even where the resources are available, using the newer scale is more cumbersome and difficult in daily practice. ${ }^{30}$ We used the Laer-modified Ross classification system, ${ }^{32}$ which uses simple bedside clinical signs and symptoms to classify the severity of heart failure. However, it is important to point out that there are limitations to using clinical parameters alone to predict outcomes in heart failure patients. ${ }^{33,34}$ Since half of the variables in the old version of Laer-modified Ross scoring system were related to the work of breathing, it may undervalue congestive heart failure symptoms. Ross himself acknowledged this problem, which led to the expansion of the system to include specific laboratory parameters for accessing cardiac physiology. ${ }^{31}$ Nevertheless, considering that most of the children in our study had heart failure due to non-cardiac disorders and that the newer scale specifically focuses on for heart failures due to cardiac pathology, we considered the older version more appropriate for our study.

In our sample, sepsis was associated with a higher likelihood of mortality. This is not surprising, since myocardial dysfunction in septic patients has been found to significantly increase mortality compared to septic patients without myocardial dysfunction. ${ }^{35}$. Sepsis can cause myocardial depression via cytokines and nitric oxidemediated cardiomyocyte hyporesponsiveness, and it can also cause direct cardiomyocyte injury or death. ${ }^{36-38}$ 
Younger children were also found to have slower recovery and relatively poorer outcomes than older children in this study. Young age is associated with longer hospitalization and higher mortality in children with heart failure. In a national survey of pediatric heart failure over a 9 year period 39 admissions for heart failure were significantly longer in children than adults, with a mean of 16.2 vs. 6.8 days, $\mathrm{p}$ $<0.001$. It is important to note that cardiac reserve is relatively lower in older children than adults, so they are less able to accommodate increased demand on the heart. ${ }^{40}$

Children with congenital heart defects and those with dysmorphic features suggestive of Down syndrome were also associated with poor outcomes. Hospitalized children with Down syndrome have a high prevalence of congenital heart disease (up to $62 \%)^{41}$

Anemia is another important comorbidity seen in both adult and pediatric heart failure patients. ${ }^{7,42}$ It can occur in more than a third of children with heart failure, as seen in our study and other studies, ${ }^{7,43}$ and its prevalence is higher in acute decompensated heart failure than in chronic heart failure. ${ }^{42}$ The etiology of anemia in heart failure is micronutrient deficiency from inadequate intake (especially vitamin B12, folic acid, and iron) and inadequate absorption. Surprisingly, anemia did not affect outcomes in our study. The fact that the $75 \%$ of our study population had a hemoglobin value $\leq 11 \mathrm{~g} / \mathrm{dl}$, which is below the -2 standard deviation cut off values for most pediatric age groups, ${ }^{44}$ could have made it difficult for us to have a suitable number of controls for comparison.

This study highlights some of the peculiarities of health care in a developing country, one of which is self-medication with both over-the-counter and alternative medicine rather than going to the hospital to seek medical help. Self-medication with both prescription and over-the-counter drugs is a common problem in developing countries, unlike in developed countries, where self-medication usually involves only overthe-counter drugs. ${ }^{45-49}$ The incidence of self-medication varies in developing countries, ranging from 12.4 to $91.3 \%$. In our patient population $43 \%$ took self-prescribed over-the-counter drugs. ${ }^{46,48,50}$ Improper self-medication may delay patients from seeking medical treatment, thereby leading to complications and increased risk of mortality. It could also lead to adverse drug effects, drug interactions, incorrect diagnosis and antibiotic resistance. ${ }^{51,52}$

Our study found a relatively higher likelihood of poor outcomes among those that used herbs, although the finding was not statistically significant. This could be due to our small sample size, which made our confidence interval very wide.
Nigerian studies have found that the herbal preparations used by traditional herbalists for treating various ailments grew high doses of various pathogenic bacteria that were resistant to many antibiotics. Large strains of fungi were also isolated from the herbal concoctions. ${ }^{53,54}$ This brings to light the potential problems of herbal medicine, i.e., not only is the therapeutic efficacy of these substances in doubt, but their unhygienic preparation leaves the finished product with pathogenic and possibly lethal microbes. If these herbs are taken by an ill child, it would be a case of double jeopardy: doing more harm to an already sick child in a bid to treat an ailment.

Another problem seen in our patients was discharge against medical advice. In pediatrics, this decision is made by parents on behalf of their children. However, requests for discharge against medical advice are encountered worldwide, and the reasons and prevalence vary by region. In developed countries, discharge against medical advice among pediatric patients is uncommon due to efficient child protection systems that protect children from actions that would endanger their well-being. ${ }^{55}$ The $5 \%$ prevalence of discharge against medical advice in our patient cohort is similar to the overall rates reported in other Nigerian studies (3.1 to $7.5 \%$ ).$^{56-58}$ The reasons for discharge against medical advice for pediatric patients in Nigerian hospitals include financial constraints (27 to $42 \%$ ), lack of perceived clinical improvement (10 to $26 \%$ ), perceived clinical improvement (22 to $27 \%$ ), the inconvenience that admission causes the parents or caregiver (7 to $8 \%$ ) and dissatisfaction with the medical care (5 to $8 \%$ ). ${ }^{56-58}$ When health care costs are paid out of pocket, as is the case in Nigeria, it leads to catastrophic expenditures and adverse outcomes, creating barriers to receiving and providing health care. It is not surprising that financial constraint is the major reason parents prematurely remove their children from the hospital; without a system to take over the continued cost of providing for the child's needs, health care workers can only play an advisory role in such cases.

These added risk factors, associated with poor outcomes seen in children with acute heart failure from developing countries, are products of the weak health care systems and social structure in developing economies. These problems require strong political will and government commitment to invest in a sustainable framework that will improve health care and social services.

Although our regression model could predict a poor outcome, it had moderate discriminatory ability, with an AUC of $64 \%$. Since the model has a role in sensitizing clinicians to the common risk factors that can adversely 
affect outcomes in children with heart failure, it can be used alongside other clinical parameters to stratify the risk of poor outcome in children with heart failure. Using the newer version of the Ross score to classify our patients might have improved the discriminatory ability of our model.

\section{Limitations of our Study}

This study has some limitations. Since the data was collected for registry purposes, it involved the limitations inherent to a retrospective study, including possible confounders that were not measured and problems with missing data.

\section{Conclusions/ Recommendations}

In conclusion, the prevalence of heart failure was $4.1 \%$, while the mortality rate was $11 \%$. Non-cardiac disorders were the most common cause of heart failure, contributing to $83 \%$ of the causes. Malnutrition was significantly associated with delays in resolution of heart failure. Management of children with heart failure should include prompt treatment of underlying sepsis and malnutrition through standard protocols to improve their clinical outcomes. Further adequately powered prospective studies are needed to identify all the risk factors associated with poor outcomes in children with heart failure.

\section{References}

1. Satou GM, Halnon NJ. Pediatric Congestive Heart Failure Treatment and Management. 2015. [Cited in 2018 March 27]. Available at:https://emedicine. medscape.com/article/2069746-treatment.

2. Hsu DT, Pearson GD. Heart failure in children. - Circ Heart Fail. 2009;2(1):63-70.

3. Masarone D, Valente F, Rubino M, Vastarella R, Gravino R, Rea A, et al Pediatric heart failure: a practical guide to diagnosis and management. Pediatr Neonatol. 2017;58(4):303-12.

4. Mejia EJ, O'Connor MJ, Lin KY, Song L, Griffis H, Mascio CE, et al. Characteristics and outcomes of pediatric heart failure-related emergency Department Visits in the United States: A Population-Based Study.J Pediatr, 2018;193:114-8.e.3.

5. Adekanmbi AF, Ogunlesi TA, Olowu AO, Fetuga MB. Current trends in the prevalence and aetiology of childhood congestive cardiac failure in Sagamu. J Trop Pediatr. 2007;53(2):103-6.

6. Anah MU, Antia-Obong OE, Odigwe CO, Ansa VO. Heart failure among paediatric emergencies in Calabar South-Eastern Nigeria. Mary Slessor. J Med. 2004;4(1):58-62.

7. Duru C, Mesiobi-Anene N, Akinbami F. Pediatric heart failure among emergency room admissions in a Tertiary Health Centre in Southern Nigeria. Nig J Cardiol. 2016;13(1):62-6.

8. Lagunju IA, Omokhodion SI. Childhood heart failure in Ibadan. West Afr J Med., 2003;22(1):42-5.

\section{Author contributions}

Conception and design of the research: Onubogu U. Acquisition of data: Onubogu U. Analysis and interpretation of the data: Onubogu U. Statistical analysis: Onubogu U. Writing of the manuscript: Onubogu U. Critical revision of the manuscript for intellectual content: Onubogu U.

\section{Potential Conflict of Interest}

No potential conflict of interest relevant to this article was reported.

\section{Sources of Funding}

There were no external funding sources for this study.

\section{Study Association}

This article is part of the thesis of master submitted by Uchenna Onubogu, from King's College de Londres.

\section{Ethics approval and consent to participate}

This study was approved by the Ethics Committee of the River State Health Research. All the procedures in this study were in accordance with the 1975 Helsinki Declaration, updated in 2013. Informed consent was obtained from all participants included in the study.

9. Weintraub NL, Collins SP, Pang PS, Levy PD, Anderson AS, Arslanian-Engoren C, et al. Acute heart failure syndromes: Emergency Department Presentation, Treatment, and Disposition: Current Approaches and Future Aims. Circulation. 2010; 122(19):1975-94.

10. Kapoor JR, Perazella MA. Diagnostic and therapeutic approach to acute decompensated heart failure. Am J Med. 2007;120(2):121-7.

11. Shaddy RE, George AT, Jaecklin T, Lochlainn E, Thakur L, Agrawal $\mathrm{R}$, et al. Systematic literature review on the incidence and prevalence of heart failure in children and adolescents. Pediatr Cardiol. 2018;39(3):415-36.

12. Koulouri S, Acherman RJ, Wong PC, Chan LS, Lewis AB. Utility of B-type natriuretic peptide in differentiating congestive heart failure from lung disease in pediatric patients with respiratory distress. Pediatr Cardiol.2004;25(4):341-6

13. Olusanya O, Okpere EE, Ezimokhai M. The importance of social class in voluntary fertility control in a developing country. . West Afr J Med.1985;4:205-7.

14. World Health Organization. (WHO). Haemoglobin concentrations for the diagnosis of anaemia and assessment of severity. Vitamin and Mineral Nutrition Information System. (VMNIS).2011;11(1):1-6.

15. MedCalc 3000. CDC Weight for Age Percentiles for Boys (2-20 years) . [Cited in 2018 June 6] . Available at: https://reference.medscape.com/ calculator/weight-age-percentile-boys. 
16. MedCalc 3000. CDC Weight for Age Percentiles for Girls (2-20 years) 2018; Available at: https://reference.medscape.com/calculator/weight-agepercentile-girls. Accessed June 6, 2018.

17. MedCalc 3000. CDC/NCHS Infant Weight for Age Percentiles (<36 months). [Cited in 2018 June 6]. Available at: https://reference.medscape.com/ calculator/infant-weight-age-percentile.

18. Animasahun A, Itiola j, Falase B, Gbelee O, Kehinde O, Odusanya O, et al. Congestive cardiac failure among Nigerian Children; Pattern and Outcome Int Cardiovasc Res J. 2015;9(3):164-8.

19. Ogeng'o JA, Gatonga PM, Olabu BO, Nyamweya DK, Ongera D. Pattern of congestive heart failure in a Kenyan paediatric population. Cardiovasc J Afr. 2013; 24(4):117-120.

20. Gebremariam S, Moges T. Pediatric heart failure, lagging, and sagging of care in low income settings: a hospital based review of cases in Ethiopia. Cardiol Res Pract. 2016;2016:7147234.

21. Massin MM, Astadicko I, Dessy H. Epidemiology of heart failure in a tertiary pediatric center. Clin Cardiol. 2008; 31(8):388-91.

22. Macicek SM, Macias CG, Jefferies JL, Kim JJ, Price JF. Acute heart failure syndromes in the Pediatric Emergency Department. Pediatrics. 2009;124(5):e898.

23. Kachaporn N, Win T. Congestive heart failure in children with pneumonia and respiratory failure. Pediatr Int.2018; 59(3):258-64.

24. Sadoh WE, Osarogiagbon WO. Pneumonia complicated by congestive heart failure in Nigerian children. East Afr Med J. 2012;89(10):322-6.

25. Kotlyar S, Olupot P, Nteziyaremye J, Akech SO, Uyoga S, Muhindo RBS, et al. Assessment of myocardial function and injury by echocardiography and cardiac biomarkers in African Children With Severe Plasmodium falciparum Malaria*. Pediatr Crit Care Med. 2018;19(3):179-85.

26. Crampin EJ, Smith NP, Langham AE, Clayton RH, Orchard CH. Acidosis in models of cardiac ventricular myocytes. Philos Trans A Math Phys Eng Sci. 2006; 364(1842):1171-86.

27. Yacoub SMR, Lang HMR, Shebbe MHN, Timbwa MHN, Ohuma EMS, Tulloh RDM, et al. Cardiac function and hemodynamics in Kenyan children with severe malaria. Crit Care Med. 2010;38(3):940-5.

28. Marwali E, Darmaputri S, Somasetia DH, Sastroasmoro S, Haas N, Portman M,A. Does malnutrition influence outcome in children undergoing congenital heart surgery in a developing country? Paediatrr Indones.2015;55(2):109-16.

29. Yoshihisa A, Kanno Y, Watanabe S, Yokokawa T, Abe S, Miyata M, et al. Impact of nutritional indices on mortality in patients with heart failure. Open Heart. 2018;5(1):2600-730.

30. Rocha Araújo FD, Silva RMF, Tonelli HAF, Guimarães AFM, Castilho SRT, Meira ZMA. Prognosis of dilated cardiomyopathy with severe heart failure according to Functional Classification Scales in Childhood . Int J Cardiovascular Sci. 2018;31(1):12-21.

31. Ross RD. The Ross classification for heart failure in children after 25 years: a review and an age-stratified revision. Pediatr Cardiol. 2012;33(8):1295-300.

32. Laer S, Mir TS, Behn F, Eiselt M, Scholz H, Venzke A, et al. Carvedilol therapy in pediatric patients with congestive heart failure: a study investigating clinical and pharmacokinetic parameters. Am Heart J. 2002;143(5):916-22.

33. Andrews RE, Fenton MJ, Ridout DA, Burch M, British Congenital Cardiac Association. New-onset heart failure due to heart muscle disease in childhood: a prospective study in the United kingdom and Ireland. Circulation. 2008; 117(1):79-84.

34. Towbin JA, Lowe AM, Colan SD. Incidence, causes, and outcomes of dilated cardiomyopathy in children. JAMA. 2006; 296(15):1867-76.

35. Charpentier J, Luyt C, Fulla Y, Vinsonneau C, Cariou A, Grabar S, et al. Brain natriuretic peptide: A marker of myocardial dysfunction and prognosis during severe sepsis. Crit Care Med. 2004;32(3):660-5.

36. RajS, Killinger JS, Gonzalez JA, Lopez L. Myocardial dysfunction in pediatric septic shock. J Pediatr. 2014; 164(1):72-77.e2.
37. Kakihana Y, Ito T, Nakahara M, Yamaguchi K, Yasuda T. Sepsis-induced myocardial dysfunction: pathophysiology and management. J Intens Care. 2016;4(1):22.

38. YuerekM, Weiss SL, Naim MY.TheFailing Myocardium in Sepsis A2 In: Chang AC, Rossano JW, Shaddy RE, Towbin JA, editors. Heart failure in the child and young adult. Boston: Academic Press; 2018. p. 445-56.

39. Wittlieb-Weber C, Lin KY, Zaoutis TE, O'Connor MJ, Gerald K, Paridon $\mathrm{SM}$, et al. Pediatric versus adult cardiomyopathy and heart failure-related hospitalizations: a value-based analysis. J Card Fail. 2015;21(1):76-82.

40. Nemergut EC. Neonatal vs adult cardiac physiology. [Cited in 2018Jun 4] Available at: https://www.openanesthesia.org/neonatal_vs-_adult_cardiac_ physiology.

41. Gratias TM, Purushottam L. Down syndrome clinical presentation. [Cited in June 4]. Availableat: https://emedicine.medscape.com/article/943216-clinical\#b2.

42. Van Aelst LN, Marjorie A, MalhaS, Thibaud L, Philippe M, Damien L, etal. Iron status and inflammatory biomarkers in patients with acutely decompensated heart failure: early inâ€ hospital phase and 30â€ day followâ€ up. Eur J Heart Fail. 2017;19(8):1075-6.

43. Goldberg JF, Shah MD, Kantor PF, Rossano JW, Shaddy RE, Kevin C, et al. Prevalence and severity of anemia in children hospitalized with acute heart failure. Cong Heart Dis. 2016;11(6):622-9.

44. Merritt BY, Curry CV. Hemoglobin concentration (Hb). 2014. [Cited in 2018 June6]. Availableat:https://emedicine.medscape.com/article/2085614-overview.

45. Yong D, Hildtraud K. Self medication among children and adolescents in Germany: results of the National Health Survey for Children and Adolescents (KiGGS). Br J Clin Pharmacol. 2009;68(4):599-608.

46. Ayanwale M, Okafor I, Odukoya O. Self-medication among rural residents in Lagos, Nigeria. J Med Trop .2017; 19(1):65-71.

47. Kombaté K, Técléssou JN, Saka B, Akakpo AS, Tchangai KO, Mouhari-Toure A, et al. Prevalence and factors associated with self-medication in dermatology in Togo. Dermatol Res Pract. 2017;2017:521831.

48. GoharUF, SK, Mehmood A. Self-medication trends in children by their parents J Dev Drugs. 2017.6(2):1-7.

49. Marwa KJ, Njalika A, Ruganuza D, Katabalo D, Kamugisha E. Self-medication among pregnant women attending antenatal clinic at Makongoro health centre in Mwanza, Tanzania: a challenge to health systems. BMC Preg.201;18(1):16. 2018 12/21;18:16.

50. Ayalew MB. Self-medication practice in Ethiopia: a systematic review. Patient Prefer Adher. 2017;11:401-13.

51. Ruiz ME. Risks of self-medication practices. Curr Drug Saf. 2010;5(4):315-23.

52. Montastruc J, Bondon-Guitton E, Abadie D, Lacroix I, Berreni A, Pugnet G, et al. Pharmacovigilance, risks and adverse effects of self-medication. Th $\tilde{A} \odot$ rapie 2016 04/01;71(2):257-262.

53. Danladi A, Inabo HI, Yakubu SE, Olonitola OS. Contamination of herbal medicinal products marketed in kaduna metropolis with selected pathogenic bacteria. Afr J Trad Complement Altern Med. 2008;6(1):70-7.

54. Adeleye IA, Okogi G, Ojo EO. Microbial contamination of herbal preparations in Lagos, Nigeria. J Health, Popul Nutr. 2005;23(3):296-97.

55. Kalburgi S, Cady R, McClymont S. Development of a clinical algorithm for threatened discharge against medical advice. Pediatrics. 2017;140(1):27.

56. Duru CO, PetersideO, Udua AO. Paediatric discharges against medical advice at a tertiary health centre in Bayelsa State, Nigeria . Niger J Paed. 2014;41(2):90-5.

57. EkeGK, Opara PI. Discharge against medical advice amongst patients admitted into the Paediatric wards of the University of Port Harcourt Teaching Hospital . Niger J Paed. 2013;40(1):40-4.

58. Oz C, Ndu I, Asinobi I, Ekwochi U,Amadi OF, Osurah CDI,Ayuk A, et al. Discharge Against Medical Advice(DAMA) Among the Paediatric Age Group in Enugu State University Teaching Hospital Parklane, Enugu. J Exp Res. 2016;4(1):55-62. 